\title{
Una antinomia protorrenacentista: secreto de estado y divulgación en los descubrimientos luso-castellanos. La cartografía (1418-1495)
}

Jesús M. ${ }^{a}$ Porro Gutiérrez

Universidad de Valladolid

Las políticas atlánticas de Castilla y Portugal motivaron, a lo largo del siglo XV, el recrudecimiento de la rivalidad de ambos estados. El Infante D. Enrique fue clave en la consolidación del proyecto ultramarino luso, enfocado en una doble vertiente: el reconocimiento — con los consiguientes derechos de soberanía — de los archipiélagos atlánticos y el intento de circunnavegación africana - con creación de bases litorales y aprovechamiento comercial- buscando una ruta hacia la India. Juan II y los Reyes Católicos llegarían al punto más álgido de la disputa — ante el proyecto colombino y sus consecuencias-, rivalizando, con astucia y sagacidad, en los planos político, diplomático, geográfico y científico. Consecuencia de la razón de Estado y la pugna luso-castellana fueron la política de sigilo (con la consecuente manipulación de crónicas, datos y cartas náuticas), el espionaje en provecho propio y la preocupación por prevenir el ajeno, alterando noticias e informes para despistar a otras potencias

Palabras Clave: Descubrimientos, Navegaciones, Secreto, Espionaje, Diplomacia, Cartografía

The Atlantic policies of fifteenth-century Castile and Portugal provoked increasing rivalry between the two states. Henry the Navigator played a key role in the consolidation of the Portuguese overseas project, a project with two broad aims: survey of the Atlantic islands (with the consequent sovereign rights), and the attempted cirumnavigation of the African coast in search of a route to India (with the establishment of coastal bases and onset of trade). John II and the Catholic Kings protagonised the high point of this dispute as a result of Columbus's voyage and its consequences, contending shrewdly on the political, diplomatic, geographical and scientific levels. A consequence of reasons of State and of this luso-castilian rivalry was a policy of secrecy (with the resulting manipulation of chronicles, facts and nautical charts), espionage in the national interest, and concern to thwart that of others, by altering information and reports so as to mislead other powers.

Keywords: Discoveries, Navigations, Secret, Spying, Diplomacy, Cartography

El desencadenamiento de la larga y fecunda etapa de los descubrimientos geográficos durante el siglo XV, motivó no sólo la rivalidad entre Portugal y Castilla por conseguir la hegemonía, sino también la necesidad de armonizar dos aspectos, a veces antagónicos, de un mismo proceso: el secreto de estado y la divulgación. En este trabajo pretendemos plantear la 
difícil coexistencia de ambos parámetros, el mayor énfasis de uno u otro - según los intereses estratégicos de lusos y castellanos-, la incidencia de la política de sigilo, la diplomacia y el espionaje en el fenómeno de los descubrimientos y su reflejo, así como el de los esquemas mentales preconcebidos - con el condicionamiento de las ideas geográficas imperantes, no siempre cercanas a la realidad-, en los acontecimientos históricos y los desarrollos cartográficos.

\section{El inicio de la expansión portuguesa: la política de D. Enrique}

Durante el reinado de Juan I de Avís comenzó el despegue de Portugal como estado moderno, con aspiraciones hegemónicas. En esa etapa se iniciaron los cambios profundos que, continuados en tiempos de sus hijos Duarte y Pedro - éste como regente de su sobrino Alfonso- conllevaron la reordenación y modernización del aparato burocrático-administrativo, el sometimiento de la nobleza y el impulso de los conocimientos y quehaceres náuticos que provocó el inicio de la expansión y de la brillante etapa de los descubrimientos geográficos. Tanto la burguesía, como una parte de la nobleza tradicional apoyaron a la Corona en esa ambiciosa labor que implicaría la implantación de una economía más diversificada, el acceso a nuevos mercados y el ascenso al rango de gran potencia para Portugal.

En lo tocante al desarrollo náutico, la expansión marítima y los descubrimientos, el personaje emblemático fue el infante D. Enrique, preocupado ante todo por el engrandecimiento de su país y el fomento de las empresas náuticas. Muy pronto decidió tomar sobre sí la responsabilidad de dirigir y auspiciar una política de desarrollo de las actividades científicas, náuticas y geográficas; por ello, ya en una fecha bien temprana (1412) contrató los servicios del prestigioso cartógrafo mallorquín Jaime Ribes (Jafuda Cresques) — quien formaría una sólida escuela—, además, el Infante se rodeó de un selecto grupo de astrónomos y pilotos, a los que patrocinó, para poder desarrollar su ideario. El largo gobierno de Juan I resultó fructífero en el campo político y su acción fue completada con la notable labor de su tercer hijo en los ámbitos científico, comercial y naval. Un primer intento portugués de consolidar nuevos avances territoriales más allá del Algarve, en África, fracasó en Tánger (1437), si bien ya se había iniciado la política de expansión atlántica, que debía ser complementada —en el ideario político del Estado - con la instalación en África 
y el dominio del estrecho de Gibraltar (para lo cual, previamente, había sido conquistada Ceuta en 1412). ${ }^{1}$

$\mathrm{Al}$ igual que Portugal - si bien con un cierto retraso motivado por la todavía inacabada reconquista, los problemas con Aragón y el fracaso de sus intereses lusos tras Aljubarrota- también Castilla experimentaba un vigoroso ascenso, al que no fue ajeno la recuperación de la marina durante los últimos años de Juan I y los primeros de Enrique III. Ya durante los años de minoría de Juan II y la oportuna regencia Castilla intensificó su presencia marítima, tanto en el Atlántico como en el Mediterráneo.

En el ámbito de los archipiélagos atlánticos, las expediciones bajomedievales fueron iniciadas por los genoveses, a los que siguieron florentinos, portugueses, castellanos y catalano-mallorquines, a lo largo del siglo XIV. ${ }^{3}$ Que Castilla y Portugal chocaran, como consecuencia de sus intereses atlánticos, en el ámbito de las Canarias, era sólo cuestión de tiempo. ${ }^{4}$

Una vez fogueado el foco de Sagres, los hombres de D. Enrique iniciaron sus exploraciones oceánicas bajo la más estricta política de sigilo; ${ }^{5}$ apenas hay comentarios en los documentos de cancillería o las crónicas, y el reflejo de aquellos viajes - en lo tocante a su proyección cartográficatardó en tener su correspondiente plasmación en las cartas planas de la época. Ya en 1418 se produjo el redescubrimiento de las islas Madeira y, de forma complementaria, D. Enrique auspició —entre los hombres de su equipo- la busca y difusión de todas aquellas noticias o indicios que pudieran reforzar, con un interesante marco teórico, la política de descubrimientos. Que se trataba de un ambicioso proyecto lo avala el papel desempeñado por el infante D. Pedro, quien durante su largo viaje por las cortes europeas reunió todas las noticias que pudo sobre relatos de intelectuales y viajeros, e incluso consiguió un interesante ejemplar de

1 Martins da Silva Marques, Joâo: Descobrimentos portugueses, Instituto de Alta Cultura, Lisboa, 1944, vol. I (1415-1460).

2 Suárez Fernández, Luis: Los Trastámara de Castilla en el siglo XV (1407-1474), vol. XV de la Historia de España coord. por Menéndez Pidal, Espasa Calpe, Madrid, 1964.

3 Bonnet Reverón, Buenaventura: "Las expediciones a las Canarias en el siglo XIV", Revista de Indias, 18, Madrid, 1944, págs. 577-610; también Porro, Jesús María: "El reflejo de las Canarias en la cartografía anterior al siglo XVI", Actas del XII Coloquio de Historia canario-americana y VIII Congreso Internacional de Historia de América (AEA), ed. del Cabildo de Gran Canaria, vol. en CD Ron, Madrid, 2000, págs. 3.305-3.322.

4 Es interesante la obra ya clásica de Pérez Embid, Florentino: Los descubrimientos en el Atlántico y la rivalidad hispano-portuguesa hasta el Tratado de Tordesillas, Escuela de Estudios Hispano Americanos (EEHA), Sevilla, 1948.

5 Realidad que confirman con su mutismo las diversas crónicas: Zurara, Goes, Pina, Resende, etc. 
mapamundi en Venecia ${ }^{6}$ que satisfizo mucho a su hermano, pues describía todas las tierras y sugería una Asia menos extendida hacia el este y un océano (Atlántico) menos ancho de lo supuesto. Paralelamente, tras la expedición de Fernando de Castro tocando en Gran Canaria (1424) —en un intento de crear bases de apoyo para la ruta de Guinea- se recrudeció la pugna luso-castellana por el archipiélago, coincidiendo con el descubrimiento de las primeras islas Azores en 1427; 7 las negociaciones diplomáticas se fueron sucediendo -incluso con la mediación pontificia- y al tiempo que los lusos despejaban la ruta hacia Guinea - tras doblar el Cabo Bojador - los andaluces comenzaron a aparecer por las Canarias.

Ya las cartas elaboradas durante las primeras décadas del siglo XV recogieron - con las limitaciones y reservas comprensibles- las principales novedades relativas a los descubrimientos y su plasmación gráfica. Saber hasta que punto las cartas del XV — diseñadas casi todas por catalano-mallorquines e italianos - se vieron afectadas por la ocultación de información o bien reafirmaron a portugueses y castellanos en sus proyectos atlánticos es una cuestión harto difícil de dilucidar, pues presumiblemente ambas cuestiones - mezcladas - formaron parte de la realidad política del mencionado proceso. La de Meciá de Viladestes, de 1413, revela características clásicas de la escuela mallorquina, pero muestra un interesante diseño de las Canarias; más especulativas resultan las cartas de los venecianos Zuane Pizzigano (1424) y Jacobo Giroldi (1426), realidad perceptible si tenemos en cuenta su no pertenencia al ámbito ibérico y la vigencia de la política de sigilo. Respecto a las noticias aparecidas en las crónicas sobre el hallazgo de islas en el Atlántico y los viajes alrededor de la costa occidental africana, adolecen de silencio, deformación o suma

6 En esa línea habría que situar la difusión, en Portugal, de obras eruditas que gozaban de enorme prestigio en los círculos intelectuales como la Imago Mundi del cardenal d'Ailly o, más tarde, la Historia Rerum de quien llegó a ser el Papa Pío II. D’Ailly, Pierre: Ymago Mundi y otros opúsculos, Alianza Ed. Biblioteca de Colón, n. ${ }^{\circ}$ 2, Madrid, 1992; Piccolomini, Eneas Silvio I: Descripción de Asia, Alianza Ed. Biblioteca de Colón, n. ${ }^{\circ}$ 3, Madrid, 1992. Respecto al enigmático mapamundi — no divulgado- que D. Pedro llevó a Portugal en 1428, fue citado en su crónica del siglo XVI por Galvâo Antonio: Tratado que compós o nobre e notavel capitâo Antonio Galvâo dos diversos e dos desvayrados caminhos por onde nos tempos passados a pimenta e especearia veyo da India ás nossas partes $e$ assi de todos os descobrimentos antigos e modernos que sâo feitos até a era de mil e quinhentos e cincoenta, Livraria Civilizaçâo, Porto, 1944.

7 Descubrimiento apenas mencionado en la correspondencia oficial y las crónicas, Gámir Sandoval, Alfonso: "La experiencia portuguesa en la cartografía del siglo XV", Estudios Americanos, XX-105, Sevilla, 1960, pág. 287. Hay una amplia exposición sobre la cuestión en Cortesâo, Jaime: O designio do Infante e as exploraçoes Atlánticas até a sua morte, vol. III de la Historia de Portugal, ed. de Peres Damiâo. 
precaución, según los casos; tal, por ejemplo, la de Zurara quien, a propósito del descubrimiento y posterior colonización de Madeira y Porto Santo — tras citar a los capitanes Joâo Gonçalves Zarco, Tristâo Vaz Teixeira y Bartolomeu Perestrello_-, apenas señala las escalas de los navíos para abastecerse en las islas; ${ }^{8}$ en el caso del paso del tan temido Cabo Bojador - doblado finalmente por Gil Eanes en 1434 - la sugestión y el intento disuasor son evidentes. ${ }^{9}$ En la carta de Andrea Bianco, de 1436, figura el desarrollo de los archipiélagos e islas míticas del Atlántico, así como en su mapamundi circular de 1448 , pero sin nombres. Sin embargo es en la carta del mallorquín Gabriel de Vallseca (1439) donde aparecen señaladas por primera vez de forma científica las Azores (con una cartela relativa a su descubrimiento en 1427).

En 1439 el príncipe heredero - futuro monarca Alfonso V- autorizó a su tío D. Enrique a iniciar el poblamiento de las Azores y en 1445 el regente D. Pedro ya había tomado diversas disposiciones al respecto, ${ }^{10}$ valorando las excelentes posibilidades que el archipiélago podía reportar respecto al aprendizaje y perfeccionamiento de la navegación atlántica; durante los siguientes años la colonización de las Azores recibió un vigoroso impulso con la presencia de flamencos ${ }^{11}$ (hasta el punto de que algunos llegaron a ser capitanes donatarios, siendo el primero Jacques de Brujas, por merced de D. Enrique en 1450). Por entonces las cartas náuticas con desarrollo atlántico mezclaban los datos reales de los descubrimientos con las sugestiones de la época, como la localización de la fantástica isla de Antilia. ${ }^{12}$ Paralelamente, continuaban las expediciones lusas en África con notable vigor, pues Nunho Tristâo llegó a la desembocadura del río Senegal (1444) y apenas un año después Dinis Dias alcanzó el

8 "Os navios partidos [Antao Gonçalves, García Homem y Diego Afonso] foran receber sua vitualha ás ilhas da Madeira, porque havia aí já grande abastança de mantimentos", Zurara, Gomes Eanes da: Crónica de Guiné, ed. Livraria Civilizaçâo, Barcelos, 1973, cap. XXXII, pág. 150.

9 Zurara: Crónica ... , cap. VIII, pág. 50: “...que despois deste Cabo nâ ha aí gente nem povoaçâo alguma; a terra nâo e menos areosa que os desertos de Libia, onde nâo ha agua, nem arvore, nem herva verde; e o mar é tâo baixo, que a uma legua de terra nâo ha de fundo mais que uma braça. As correntes sâo tamanhas, que navio que lá passe, jamais nunca poderá tornar".

10 Gámir: "La experiencia ...", págs. 288 y 289.

11 Paviot, Jacques: "Les relations économiques entre le Portugal et la Frandre au XV $\mathrm{XV}^{\mathrm{o}}$ siècle", en Economia e comércio marítimo, vol. III del Congresso Internacional Bartolomeu Dias e a sua época, Porto, 1989, págs. 531-539; también Verlinden, Charles: "Formes féodales et domaniales de la colonisation portugaise dans la zone atlantique aux $\mathrm{XIV}^{\mathrm{o}}$ et $\mathrm{XV}^{\mathrm{o}}$ siécles et spècialemente sous Henri le Navigateur", Revista Portuguesa de História, IX, Lisboa, 1960, págs. 18-33.

12 Vigneras, Louis André: "La búsqueda del Paraíso y las legendarias islas del Atlántico", Cuadernos Colombinos, 6, Valladolid, 1976. 
Cabo Verde (punto más occidental del continente); la confusión geográfica corría a la par del cambio en la realidad etnográfica: la tierra de los moros daba paso a la de los negros ${ }^{13}$ y creían haber encontrado uno de los afluentes occidentales del río Nilo (el Senegal), ${ }^{14}$ fijando además la fuente de un segundo curso tributario. ${ }^{15}$ Cuando Gonçalves Zarco cruzó el Cabo Verde, navegando más al sur de la isla de Beseguiche llegó a otro cabo, ${ }^{16}$ donde comprobó la naturaleza de las $\operatorname{costas}^{17}$ y la necesidad de corregir las cartas poco antes realizadas. ${ }^{18}$ En ese ámbito y en tal situación, el propio Zurara manifiesta una postura de silencio y escepticismo en lo concerniente al reino de Mali y el comercio aurífero. ${ }^{19}$ Es probable que en 1446 se produjera un viaje clave pero difícil de interpretar por el laconismo y la manipulación de las fuentes: D. Enrique envió una expedición con varios objetivos. El deseo de conseguir perfilar mejor los accidentes costeros en las cartas marinas es evidente, pero ¿se trataba, también, de despistar a los posibles rivales - castellanos fundamentalmente- alterando deliberadamente las escalas y perfiles de los mapas? o ¿acaso se había producido ya la manipulación cartográfica y ahora convenía establecer, en

13 Zurara: Crónica ..., cap. LIX, pág. 253, afirma que navegaron "tanto que passaram á terra de Zaara, dos Mouros que sâo chamados Azanegues”; cap. LX, págs. 255 y 256: “... passada ... a terra de Zaara ... conheceram que ali se começava a terra dos Negros ... esta gente desta terra verde é toda negra, e porem é chamada terra dos Negros, ou terra de Guiné, por cujo azo os homens e mulheres dela sâo chamados Guineus, que quer tanto dizer como negros".

14 Ibidem, cap. LX, pág. 256: “... bem conheceram que eran perto do rio do Nilo, da parte donde vem sair ao mar do ponente, ao qual rio chamam de Çanaga ...”.

15 Ibidem, cap. LXI, pág. 256: “... e que chega ás outras areias que sâo além de Mauritania, contra Etiopia, que se esconde outra vez, e que vae assim escondido por espaço de XX jornadas, até que é dentro da terra de Etiopia, que sae de todo sobre a terra, mostrando que sae de uma fonte, tal como a outra de Mauritania, que se chama Nigris, onde se criam isso mesmo aquelas mesmas animalias ..." [cocodrilos].

16 Ibidem, cap. LXX, pág. 316: “... onde havia muitas palmeiras secas sem rama, e poseram nome áquele cabo, o Cabo dos Matos...”. Es el que Soligo cita Capo Roixo, actual Roxo.

17 Ibidem; cap. LXXVI, págs. 321 y 322: "Diziam ainda que as terras eram areosas e sem alguma povoaçâo; e bem é que quanto ás areias nâo se enganavam de todo, mas todavia nâo em tamanho grau; e da povoaçâo bem vistes o contrario ... como quer que as suas povoaçôes a maior parte sâo aldeias, e vilas mui poucas ... nâo serâo por todas, entre vilas e lugares afortalezados para defesa, até cinquenta".

18 Otra dificultad añadida reside en la presumible censura del siguiente pasaje de Zurara: Crónica ... , cap. LXXVI, pág. 322: "Enganavam-se ainda na profundeza do mar, que tinham em suas cartas que eran praias tâo baixas, que a uma legua de terra nâo havia mais que uma braça de agua; o que se achou por o contrairo, que os navios tiveram e teem assaz de altura para seu marear, tirando certos baixos, e assim se fez Essacanas que aí ha em certas restingas, segundo agora achareis nas cartas do marear que o Infante mandou fazer".

$19 \mathrm{Al}$ igual que hiciera respecto a los mercados establecidos en las fortalezas costeras de Arguim y Río del Oro, Zurara: Crónica ... , cap. LXXVII, pág. 327. 
secreto, el desarrollo auténtico de las cartas? $?^{20}$ Es evidente que las 600 leguas de costa africana, teóricamente recorridas por los lusos según Zurara, constituyen una distancia excesiva, al igual que las 450 al sur de Bojador; tal exageración contrasta con el dato - más creíble aunque algo abultado - de las 110 leguas recorridas al sur de Cabo Verde. ${ }^{21}$ Pocos años después Alvise de Cadamosto - otro de los hombres de D. Enrique- descubrió las islas de Cabo Verde.

\section{El ámbito atlántico: islas reales y fantásticas. Del optimismo a la ralentización africana de los años sesenta y setenta}

Pero la política expansiva no fue limitada al campo africano; al mismo tiempo que los portugueses afianzaban sus periplos de exploración en Senegambia y avanzaban hacia Guinea, dieron un notable impulso a sus navegaciones en otro ámbito estratégico: el amplio espacio situado al oeste de los archipiélagos atlánticos ya descubiertos. No vamos a entrar en la polémica $-\mathrm{y}$ bibliográficamente prolífica - cuestión de los posibles predescubrimientos lusos en el océano, ${ }^{22}$ más bien nos ceñiremos a la importancia que las ideas y los rumores de la época tuvieron en la difusión de la política atlántica y la ampliación de los descubrimientos y los desarrollos cartográficos: la creencia en la existencia de la isla Antilia, mezclada con la leyenda de las Siete Ciudades y otras sugestiones insulares, aumentó la curiosidad y excitación de los marinos por adentrarse en el Atlántico, así

20 La versión de Zurara: Crónica ... , cap. LXXVIII, pág. 332, es oscura y se presta a varias interpretaciones: las carabelas fueron "alem do cabo 450 leguas. E acha-se que toda aquela costa vai ao sul com muitas pontas, segundo que este nosso Principe mandou acrecentar na carta do marear. E é de saber que o que se sabia em certo da costa do mar eram 600 leguas; e sâo acrecentadas sobre elas estas 450; e o que se mostrava no mapa-mundi, quanto ao desta costa, nâo era verdade, que o nâo pintavam senâo á aventura; mais isto que agora é posto nas cartas foi cousa vista por olho, segundo já tendes ouvido".

21 Tal fue según Zurara: Crónica ..., cap. LXXXVII, pág. 368, el periplo de la carabela de Álvaro Fernandes, "e toda sua rota é geralmente ao sul".

22 Entre otras cuestiones, porque no hay pruebas irrefutables ni a favor ni en contra y actualmente la historiografía portuguesa está sometiendo a una reconsideración crítica todo el fenómeno de los descubrimientos atlánticos. De la bibliografía "clásica" destacamos Cortesâo: $O$ designio ... ; Cortesâo, Armando: Historia da Cartografia Portuguesa, Coimbra, 1969; Teixeira da Mota, Avelino: “Cristóbal Colón y los portugueses", Cuadernos Colombinos, 5, Valladolid, 1975, págs. 33-55; Ramos Pérez, Demetrio: "Los contactos trasatlánticos decisivos, como precedentes del viaje de Colón", Anuario de Estudios Atlánticos, 17, Madrid-Las Palmas, 1971, págs. 467-532; Gámir: "La experiencia ..." ; Martins da Silva: Descobrimentos ... ; Cortesâo, Armando y Teixeira da Mota, Avelino: Portugaliae Monumenta Cartographica, Lisboa, 1960, 6 vols. 
como el deseo de las cortes portuguesa y castellana de ampliar el ámbito y la frecuencia de sus navegaciones, aprovechando el sistema favorable de vientos y corrientes, y buscando (o analizando) indicios sobre la posibilidad de hallar nuevas tierras al occidente del océano. Fue en ese ambiente y circunstancias cuando se realizaron los periplos de Diogo de Teive, así como las donaciones teóricas de la Corona portuguesa (recordemos que en el mapa de Bianco, de 1448, aparece al suroeste de Cabo Verde una Ixola Otinticha, cuya posición y forma recuerdan el litoral del noreste brasile$\tilde{n} \mathrm{O}^{23}$ ). En su primer periplo Teive zarpó de Fayal navegando al suroeste y a su vuelta descubrió las islas de Flores y Corvo (completándose así el conocimiento de las Azores); en el segundo (1452) recorrió una extensión marítima al oeste de Irlanda y presumiblemente llegó al banco de Terranova. ${ }^{24}$ Poco después, en 1457, Alfonso V donaba al Duque de Beja las islas que se descubriesen entonces, si bien a raíz del viaje de Gonçalo Fernandes de Tavira - quien navegando al noroeste de Madeira creyó ver una isla, en 1462 - hizo una rápida concesión al Duque de Viseu y otra doble a Joâo Vogado. ${ }^{25}$ Era tan firme la creencia lusa de poder descubrir nuevas tierras a Poniente, que continuaron las donaciones acompañadas de ciertas gestiones ante la corona danesa, desarrolladas en el mayor de los sigilos; ${ }^{26}$ así, en 1473, Ruiz Gonçalves da Camara consiguió teórica donación de las islas que pensaba descubrir en el océano, completada —al año siguiente- con la convalidación de exploraciones en Guinea. El propio Alfonso V decidió, en 1475, premiar los servicios de Fernâo Telles con la concesión de las islas

23 Ignoramos cual fue la fuente de Bianco, ni como pudo reflejar esa idea sorprendente. Es evidente que tal concepto debe relacionarse con un proyecto general derivado de la creencia en tierras situadas al oeste del Atlántico. Según el cronista Galvâo: Tratado ... , poco antes de la mencionada fecha se descubrió una tierra hacia occidente.

24 Cortesâo, Jaime: "El viaje de Diogo de Teive", Cuadernos Colombinos, 5, Valladolid, n. ' 5, 1975, págs. 11-29. Para una visión general de las navegaciones atlánticas en la época son interesantes Albuquerque, Luis: Os descobrimentos portugueses, Lisboa, 1982 e Historia de la navegación portuguesa, Mapfre, Madrid, 1992; Céspedes del Castillo, Guillermo: La exploración del Atlántico, Mapfre, Madrid, 1991; Fernández Armesto, Felipe: Antes de Colón (Exploración y colonización desde el Mediterráneo hacia el Atlántico, 1229-1492), Cátedra, Madrid, 1993.

25 Según recoge Gámir: "La experiencia ...", pág. 290, tales islas "segundo a carta de marear, sao chamadas uma Lono e outra Caprária”. No se especifica en qué carta fueron dibujadas.

26 Larsen, Sofus: "La Découverte du Continent de L’Amérique Septentrionale en 1472-1473 pour les Danois et les Portugais", Separata del Boletim da Classe de Letras, Coimbra, vol. XV de la Academia das Ciencias de Lisboa, 1922. El contacto entre portugueses y daneses arranca de varias décadas antes, y presumiblemente también el inicio de relaciones diplomáticas o de una colaboración más estrecha, pues Zurara: Crónica , cap. XCIV, pág. 396, cita el caso de Vallarte (gentilhombre de la casa del rey Cristóbal), quien al servicio de D. Enrique viajó con Fernán Alfonso hasta Cabo Verde, navegando más al sur. 
que hallase -él o sus servidores- en el océano, con exclusión de la zona de Guinea. ${ }^{27}$

Respecto a la cartografía surgida como consecuencia de los viajes portugueses a Guinea, la ya mencionada política de sigilo practicada por la corte, al condicionar la permanencia de las fuentes y su fiabilidad, ha transformado en enormemente complejo el seguimiento de las nuevas realidades geográficas y, particularmente, el estudio y análisis de los mapas africanos y atlánticos. No olvidemos que el propio D. Alfonso, adoptando una postura tan astuta como prudente, solicitó del reputado cosmógrafo Fra Mauro el camaldulense de la comunidad de Murano- la realización de un mapamundi que reflejara la idea de África y, particularmente, los avances operados por sus súbditos en la navegación de Guinea (la doble intención es evidente al solicitar una determinada información gráfica que, por otro lado, se oculta a quien se pide, pues ningún boceto ni apunte portugués fue enviado al fraile, quien presumiblemente tuvo que basarse en su conocimiento de los clásicos — Heródoto, Estrabón-, complementado con el de algunas piezas fundamentales en la cartografía del XIV y primera mitad del XV quizás los mapas de Marino Sanudo, Pietro Vesconte, el anónimo conocido como Laurenciano-Mediceo, el de Meciá de Viladestes y el de Andrea Bianco - para satisfacer la petición regia). En su planteamiento técnico, el mapa de Fra Mauro (1458 o 1459) recuerda más a los de Sanudo y Vesconte (sobre todo los litorales africanos y el sur de Asia) que al de Bianco; ${ }^{28}$ manifiesta, empero, una doble mejoría en la representación africana: 1) la parte occidental presenta una mayor fiabilidad en el delineado del tramo entre Ceuta y Sierra Leona; 2) el litoral oriental acusa una inflexión más suave una menor oblicuidad — que en sus predecesores; además, el planteamiento de la punta meridional está más conseguido, si bien el tamaño de Madagascar es exagerado y la isla está muy pegada al continente.

Apenas pudo D. Enrique extraer consecuencias del mapa de Fra Mauro, pues en 1460 falleció, cuando sus hombres llegaban al litoral de Sierra Leona. El vacío dejado por la muerte del Infante — genuino impulsor de las empresas descubridoras-, unido a diversos problemas técnicos y políticos, llevó a una ralentización y un replanteamiento de las exploracio-

27 Real Academia de la Historia: Colección documental del Descubrimiento, 1470-1506, coord. por Pérez de Tudela, Juan, Mapfre, Madrid, 1994; vol. I, docs. n. ${ }^{\circ} 9$ y 10, págs. 30-34.

28 En este sentido sorprende la afirmación de Crinó, Sebastiano: Come fu Scoperta l'America, Milán, 1943, pág. 86, de que el autor material del mapa — según el Abad del Monasterio de San Miguel de Murano- fue el propio Bianco. 
nes africanas: Lisboa sustituyó a Sagres como centro de referencia, la Corona asumió directamente los asuntos africanos y, durante casi dos décadas, los portugueses se contentaron con afianzar su presencia - beneficiándose del lucrativo comercio - en el tramo comprendido entre la costa de la Pimienta (Liberia) y el litoral oriental del Golfo de Guinea (CamerúnGabón); la guerra con Castilla y la nueva situación creada por el cambio de hemisferio y la continuación de la costa hacia el sur (problema de vientos, corrientes y falta de referencia de la Estrella Polar) influyeron en la aparente lentitud de esos años. Resulta bien difícil seguir las huellas de la cartografía lusa de la época — ante la vigencia de la política de censura y manipulación de crónicas, secuestro o desaparición de mapas, tratados de geografía, de ciencia náutica, "regimentos" y diarios de a bordo-, pero la concienzuda labor de sigilo no pudo impedir que hubiera algunas filtraciones, pues varias cartas italianas de esos años recogieron no pocos datos de las exploraciones africanas. Esos testimonios cartográficos valiosos corresponden, fundamentalmente, a Soligo y Benincasa, si bien hay algunos anónimos. La carta de Soligo (hacia 1465) delinea el litoral atlántico africano comprendido entre el actual cabo Rhir (en Marruecos) y el archipiélago de las Bijagós (en Guinea Bissau); en ella aparecen las Canarias y las islas de Cabo Verde, los topónimos de los principales accidentes geográficos y los ríos Senegal y Gambia; el planteamiento general es notable por su minuciosidad y calidad. Dos cartas, de un mismo atlas (1468), obra de Gracioso Benincasa, muestran el tramo costero entre Ceuta y el Cabo Blanco - con interesante desarrollo de lugares y topónimos, y atención preferente a la ubicación de los archipiélagos (Azores, Madeira y Canarias)—, y el correspondiente entre el Cabo Blanco y la isla Sherbro (en Sierra Leona), siendo novedosa y muy interesante la representación del espacio situado al sur de las islas Bijagós; ante la ausencia de ejemplares portugueses, ignoramos cual pudo ser el modelo de ambas cartas. Uno de los pocos ejemplos conservados de cartografía portuguesa, sobre los periplos africanos, corresponde a una carta anónima ${ }^{29}$ que recoge los conocimientos lusos del litoral occidental, desde

29 Aparece reproducida y comentada en Cortesâo-Teixeira da Mota: Portugaliae ... , tomo I, estampa n. ${ }^{\circ}$ 2; se encuentra en la Biblioteca Estense de Módena. La existencia de cuatro mapas lusos, elaborados durante las últimas décadas del siglo XV ha sido planteada por Albuquerque, Luis de y Marques do Santos, Annie: "Los cartógrafos portugueses", en Chandeigne, Michael (Dir.): Lisboa extramuros, 1415-1580. El descubrimiento del mundo por los navegantes portugueses, Alianza Ed, Madrid, 1992, págs. 71-80. Un segundo ejemplar anónimo también fue incluido y comentado en la Portugaliae ... tomo I, estampa n..$^{\circ}$ y se encuentra entre los fondos del Arquivo Nacional da Torre do Tombo, aunque es ajeno al mundo africano (excepto en el reflejo de su litoral correspondiente al Mediterráneo occidental). 
Ceuta hasta poco más al este del límite actual entre Benin y Nigeria; allí figuran datos de los viajes realizados hasta 1471; el delineado es bastante preciso, la toponimia muy completa, si bien a partir del tramo relativo a la frontera entre Liberia y Costa de Marfil (Cabo Palmas) hay menos nombres, pero no se interrumpe el trazado costero; la inflexión del Cabo Tres Puntas está bien señalada - reforzada con una bandera de soberanía- y el último lugar citado en la carta es el río do Lago (posiblemente el Ogún en la actual Lagos). Las exploraciones en la parte más profunda del Golfo de Guinea se desarrollaron con rapidez hasta 1475 (coincidiendo allí el doble problema de la guerra luso-castellana y el cambio de hemisferio): Joâo de Santarem no sólo llegó a la desembocadura del río Níger, también descubrió las islas de Príncipe, Sâo Tomé y Anno Bom, sobrepasando ahí la línea ecuatorial; enseguida Fernâo Poo tocó en la Formosa — rebautizada con su nombre-, Lopo Gonçalves alcanzó la costa de Gabón (Cabo López, cerca de $1^{\circ}$ latitud sur) y Rui de Sequeira desplazó el punto más meridional de los periplos africanos al Cabo de Santa Catalina (en el ramal meridional del río Ogooué o quizás en la actual punta Iguéla, antes Setté Cama).

\section{El dinamismo de Juan II y la culminación del proyecto africano}

Tras la muerte de D. Alfonso, el ascenso al trono de Portugal de Juan II supuso el definitivo impulso de la empresa africana; durante los últimos años del reinado de su padre ya se había ocupado de los asuntos africanos, ${ }^{30}$ madurando rápidamente su proyecto: el circuito comercial había sido establecido en la amplia costa de la Pimienta, la del Marfil, la del Oro y la de los Esclavos, pero fue reforzado con la fundación del castillo de San Jorge de la Mina. También se acometió la navegación de altura con el cambio de itinerarios (doble "volta"), de buques y de métodos de referencia astronómica. La energía del nuevo monarca dio rápidos frutos: en su largo viaje de 1482-1484 Diogo Câo descubrió la desembocadura del río Zaire (el Manicongo, remontando un tramo), pasó el Cabo Lobo (Santa María) y su tenacidad le permitió alcanzar — pese a las adversas condiciones de vien-

30 Comenta Madeira Santos, M. ${ }^{\mathrm{a}}$ Emilia: "Os africanos e o mar: conhecimento e práticas à época da chegada dos portugueses", sep. n. 241 del Centro de Estudos de História e Cartografia Antiga-Instituto de Investigaçâo Científica Tropical, Lisboa, 2001, pág. 11, que el futuro rey aprendió deprisa las cuestiones relativas al comercio de larga distancia, demostrando su conocimiento del antiguo comercio caravanero transahariano y del reciente, a lo largo de la costa occidental africana. 
tos y corrientes - Angra do Salto (Punta da Marca en la Bahía de los Tigres) o quizás hasta el Cabo Frío; en su segundo viaje de 1485-1486 llegó hasta el Cabo Padrâo (Cruz). Los conocimientos lusos en aquella etapa de las navegaciones africanas aparecen bien reflejados en una excelente carta de Pedro Reinel, elaborada presumiblemente en 1484 o $1485,{ }^{31}$ que muestra un diseño muy original, con el litoral atlántico africano dividido en dos segmentos: uno incluye el tramo comprendido entre Ceuta y la fortaleza de Sâo Jorge da Mina; el segundo - situado en la tierra continental correspondiente al anterior- desarrolla el litoral desde allí hasta el Cabo do Padrom (Ponta do Padrâo justo al sur del río Manicongo).

Juan II mereció el apelativo de Príncipe Perfeito: en su talante mostró una admirable mezcla de audacia y cautela; acostumbraba a decidir tras madurar sus planes; prototipo de gobernante renacentista, concedió prioridad a la razón de Estado sobre los argumentos morales; así, creó una red de información que abarcaba las principales cortes europeas, prestando especial atención a aquellas cuyos proyectos o conocimientos podían interesarle para su empresa descubridora (Castilla, Aragón, Francia, repúblicas italianas, Estado Pontificio): para ello no reparó en gastos, recompensando generosamente a sus confidentes. ${ }^{32}$ Paralelamente, el monarca reforzó la política de sigilo, con diversas restricciones relativas a cuestiones relacionadas con los descubrimientos, decretando - y aplicándolas — duras penas para los transgresores. ${ }^{33}$

31 Puesto que la carta refleja el descubrimiento del río Zaire por Câo, en el transcurso de 1483, y las noticias no llegaron a Lisboa hasta finales de ese año o comienzos del siguiente — mientras Câo seguía explorando hacia el sur-, no puede ser anterior a 1484 y, a su vez, difícilmente posterior a 1485 , pues los hombres del segundo viaje de Câo regresaron a Lisboa en 1486 con la información cartográfica correspondiente sobre el litoral hasta el Cabo do Padrâo (el Cruz) y la carta no contiene ese tramo, siendo el límite meridional de su trazado la Ponta do Padrâo situada inmediatamente al sur del río Zaire. El mapa, firmado por Reinel, fue hallado en los archivos departamentales de la Gironde en 1960, la misma fecha de edición de la Portugaliae, lo que explica su ausencia en ella.

32 El Libro del conoscimiento de todos los reinos \& tierras \& señoríos que son por el mundo ...ed. de Jiménez de la Espada, Marcos, Madrid, 1877, recoge una cita del mozo de escribanía del rey: "no solamente hacía dádivas a sus criados y naturales, sino que en los reinos extranjeros ... y otras muchas partes, muchas y grandes personas recibían de él en cada año muchas y grandes dádivas secretamente; de los cuales recibía muchos y grandes avisos, necesarios a su servicio y Estado".

33 Es bien conocido el episodio del piloto y los dos marinos que, tras huir de la Mina, intentaron vender algún secreto relacionado con la empresa; el primero fue interceptado en Portugal y descuartizado públicamente en Évora, como escarmiento y advertencia pública; agentes de D. Juan capturaron una noche a los marineros, ya en Castilla, apuñalándolos ante la imposibilidad de regresar con ellos prisioneros. La cuestión de la política de sigilo fue planteada con erudición por Cortesâo, Jaime: A Política de Sigilo dos Descobrimentos, Lisboa, 1960; resulta también interesante la obra de Bensaude, Joaquim: Lacunes et surprises dans l'histoire des découvertes maritimes, Coimbra, 1930. 
El avance en el conocimiento del litoral africano motivado por los últimos periplos portugueses ${ }^{34}$ aparece notablemente reflejado en un atlas portulano veneciano ${ }^{35}$ que sorprende por su exactitud y supone una evidencia más en la doble realidad ya mencionada: tuvo que haber cartas lusas que sirvieran de base a las italianas sobre África y, pese a la rigurosa política de sigilo, ${ }^{36}$ continuaba vigente la labor de espionaje y compraventa de secretos de Estado, en materia de descubrimientos geográficos y cartografía. En el mencionado atlas veneciano, hay varios mapas africanos muy interesantes, ${ }^{37}$ presumiblemente elaborados en 1489 . Uno recoge - con minuciosidad y abundancia de topónimos - el litoral comprendido entre Senegambia y el Cabo de Santa Catalina. Otros dos — casi idénticos- desarrollan la costa atlántica entre Arguim y Cabo Frío, con más espacios en blanco al sur del Cabo Santa Catalina; precisamente ese tramo de costa hacia el sur sorprende, no obstante la escasez de topónimos, por la fidelidad y notable precisión en su diseño (pese a los pocos años transcurridos desde los viajes de Câo). Dos mapas más desarrollan el ámbito comprendido entre el delta del Níger (a la altura de la actual Warri) y el Cabo Frío (el primero), y presumiblemente el Cruz (el segundo). El parecido entre ambos es muy notable y las diferencias son imperceptibles a simple vista, pero tras un análisis minucioso del delineado costero y los topónimos se observa que constituyen dos versiones, casi idénticas — qui-

34 Para todo lo relacionado con la cartografía lusa de la época, Cortesâo, Armando: História da Cartografia Portuguesa ; Pinheiro Marques, Alfredo: Origem e desenvolvimento da Cartografia Portuguesa na época dos descobrimentos, Imprensa Nacional-Casa da Moeda, Lisboa, 1987.

35 En el Atlas de los descubrimientos geográficos, ed. Plaza \& Janés, Verona, 1992, coord. por Fernández Armesto, Felipe, figura (cap. 12, pág. 64) la fecha de 1480 como la de realización del atlas, pero el segmento meridional de costa que recoge (con sus topónimos y la boca del Zaire) no fue conocido por los portugueses hasta el viaje de Câo de 1482-1483, luego parece lógico pensar que su elaboración responda a una fecha más tardía. La fuente de información cartográfica del atlas veneciano debió ser el mencionado mapa de Pedro Reinel, pues tampoco es cierta la aseveración de la ausencia de mapas lusos sobre África anteriores a 1492 (aparte del anónimo de hacia 1471 y el de Reinel, ya citados, hay otro de Jorge de Aguiar, firmado y fechado en 1492, que fue hallado en 1966 cuando se hizo una donación a la Universidad de Yale, motivo por el que no aparece en la Portugaliae).

36 Algunos años después (en 1504) se estipulaba que, en las cartas de navegar y globos, el límite africano representado debía fijarse en las islas de Príncipe y Santo Tomé; además, en las leyes manuelinas se prohibía a los pilotos portugueses servir en el extranjero.

37 Algunos estudiosos han considerado anónimas estas cartas italianas sobre África; otros han pensado en Gracioso Benincasa o Soligo como realizadores. Esta última posibilidad es defendida por Randles, W.G.L.: "La configuration cartographique du continent africain avant et après le voyage de Bartolomeu Dias: hypothèses et enseignements", en Navegaçôes na segunda metade do século XV, vol. II de las Actas del Congresso Internacional Bartolomeu Dias e a sua época, Porto, 1989, págs. 111-119. 
zás original y copia—, del mismo espacio físico africano. Estos dos ejemplares recogen - partiendo de la Bahía de Benin - el amplio litoral reconocido por Diogo Câo en su primer viaje; ante su buen planteamiento cartográfico, con excelente desarrollo de los accidentes costeros y verídica - aunque no muy abundante - toponimia, cabe preguntarse como pudo ser vulnerada la política de sigilo y con qué frecuencia se dieron casos de transmisión de información, evidentemente, no siempre con desarrollos cartográficos; en este caso no conocemos la posible fuente portuguesa, pero no debía ser fácil burlar las normas, pues en ese año de 1489 y consumado ya el periplo de Bartolomeu Dias, ${ }^{38}$ tan sólo los diversos mapas de Heinrich Hammer (el Enricus Martellus del mundo renacentista) desvelaron - en el plano cartográfico - los secretos portugueses de la navegación africana. Dias llegó a finales de 1487 hasta Angra Pequeña y tras ser arrastrado al sur por una fuerte tempestad comprobó, al enderezar el rumbo al noreste, que había pasado la orientación meridional de la costa; a la altura del Río Infante regresó, doblando el Cabo Agujas y el Tormentoso (al que el monarca denominaría de Buena Esperanza). Pensando en la deseada circunnavegación africana, Juan II había destacado — varios meses antes de la salida de Dias- dos emisarios a Oriente: Afonso de Paiva y Pero de Covilham, quienes debían recorrer las regiones oportunas y acopiar el mayor cúmulo de información posible sobre las condiciones de navegación en el Océano Índico y la orientación de la costa oriental africana; llevaban una carta marina para utilizar como base y guía en sus indagaciones. ${ }^{39}$ Poco después del regreso de Dias a Lisboa, informando de la apertura de la ruta índica, llegó un emisario de Covilham, con un dictamen favorable respecto a la navegación hacia la India, tomando como referencia la isla de la Luna (Madagascar) y Sofala, y remitiendo la carta marina que le proporcionaron, marcando sobre ella los nombres de los lugares que había visitado ${ }^{40} \mathrm{y}$, presumiblemente, corrigiendo errores o aportando novedades. El material y los conocimientos adquiridos serían muy útiles en la preparación y el desarrollo de la futura expedición de Vasco da Gama hacia la India.

\footnotetext{
39 No sabemos qué tipo de carta; Levillier, Roberto: América la bien llamada, Kraft, Buenos Aires, 1948, vol. I, pág. 46, cita "una carta marina sacada de un planisferio"; Randles: "La configuration ...", pág. 118, menciona "une carte marine copiée d'une mappemonde".

40 Lopes de Castanheda, Fernâo: História do Descobrimento \& Conquista da Índia pelos portugueses, Lisboa, 1551, libro I, cap. I, págs. 2-4.
} 1987.

38 Sobre el personaje, Fonseca, Luis Adâo da: O essencial sobre Bartolomeu Dias, Lisboa, 
Volviendo a la cartografía del citado Hammer, partiendo del clásico modelo ptolemaico, su configuración del mundo ofrece dos variantes en África y el Extremo Oriente; ${ }^{41}$ aunque quizá pudo consultar los mapas del ya citado atlas veneciano - contemporáneos a los suyos-, sorprende la precisión en el desarrollo de los litorales de la fachada occidental africana, si bien también es notable el reflejo de topónimos; la franja oriental, desprovista de nombres ${ }^{42}$ es claramente ptolemaica hasta el Prasum Promontorim y hacia el sur (sureste primero y luego suroeste) difiere del anterior; en el extremo meridional se señala la comunicación interoceánica.

\section{La intrusión colombina causa del renovado interés castellano en el Atlántico}

Retrocedamos unos pocos años, para situarnos de nuevo en el ámbito de las navegaciones atlánticas, al oeste de los archipiélagos. Al finalizar la guerra luso-castellana, las negociaciones diplomáticas oportunas sancionaron las respectivas esferas de influencia y áreas de soberanía, plasmadas en los acuerdos alcanzados en el Tratado de Alcaçovas de 1479:43 al sur de las Canarias Portugal conservaba su ámbito de soberanía en África, mientras Castilla mantenía sus derechos sobre islas o tierras situadas como prolongación de las Canarias hacia Occidente. Por añadidura, la expedición de una nueva Bula Pontificia blindaba a los portugueses en sus intereses africanos. Bien pronto la ambigüedad observada en la delimitación de la jurisdicción atlántica crearía problemas.

En 1484 un piloto entonces desconocido, Cristóbal Colón, se presentó ante Juan II, proponiendo un plan para llegar al Extremo Oriente navegando por Occidente; el Monarca no vio con buenos ojos la jactancia y exageradas peticiones de mercedes del advenedizo, pero, cauto, decidió convocar a sus

41 Porro, Jesús María: "La cartografía ptolemaica del sureste asiático y su variante martelliana: planteamiento, consideraciones críticas y desarrollo de una hipótesis reinterpretativa”, Revista Complutense de Historia de América, 27, Madrid, 2001, págs. 327-356, especialmente 342 y 343 para el planteamiento cartográfico de Martellus.

42 Es evidente que, transcurrido apenas un año desde la recepción en Lisboa de los informes de Covilham, y siendo un asunto privado — al contrario del recibimiento público a Dias, contemplado por el propio Colón-, difícilmente pudo haber filtraciones en ese tema.

43 El tratado fue refrendado en Toledo, al año siguiente: Capítulos relativos a las posesiones y navegaciones de castellanos y portugueses en el Atlántico, en Colección documental del Descubrimiento , vol. I, n. ${ }^{\circ} 12$, págs. 41-45. 
consejeros científicos ${ }^{44}$ a quienes pidió su opinión; ellos desestimaron el proyecto y si bien el Rey quedó satisfecho, no perdía de vista que, desde mediados de siglo, eran continuos los rumores - pese a los fracasos cosechados - sobre la existencia de islas y tierras a Poniente, adentrándose en el Atlántico. Tan es así que, apenas dos años después de la petición colombina, D. Juan autorizó a Fernâo Dulmo - uno de los flamencos de la colonia de Fayal, nacionalizado luso- a capitanear una expedición hacia Occidente, pero la prudencia y el excepticismo del Rey le llevaron a exigir que aquel costeara los gastos de la empresa, a cambio de generosos beneficios y donaciones si resultaba exitosa (así, D. Juan, comprometido con la empresa africana que absorbía notables gastos y energía, aunque dudara de la existencia de islas en el occidente atlántico, se dejaba tentar por la suerte, sin exponer las arcas del Estado en una empresa incierta). En su proyecto de acceder a la isla de las Siete Ciudades, o a cualquier otra, contemplaba Dulmo una asociación con Afonso do Estreito ${ }^{45}$ y la participación de un cierto "caballero alemán" que presumiblemente debía ser Martín Behaim. ${ }^{46}$ Puesto que Dulmo no acometió la empresa, las mercedes pasarían a Joâo Gonçalves do Arco; nada se sabe de su expedición, el caso es que los lusos no pudieron confirmar la situación de las supuestas islas atlánticas en mapas de la época (los de Benincasa de 1463 y 1476, el de Roselli de 1466, el de Albino de Cánepa y el de Jaime Bertrán de 1480, o los anteriores de Andrea Bianco). No obstante aquel fracaso, el inquieto y aventurero Behaim, seducido por el ambiente náutico que se vivía en Portugal y contagiado del entusiasmo general, deseaba participar en proyectos sobre viajes y descubrimientos: al iniciar su estancia en Portugal había establecido contacto con la colonia flamenca de Fayal y pronto tomó parte en la expedición de Joâo Affonso d'Aveiro a Benin (1484-1485) llegando hasta el Congo; $;{ }^{47}$ de vuelta a

44 Eran estos Diego Ortiz de Calzadilla, Obispo de Tánger, el médico real Rodrigo de Pedras Negras y el judío español José Vizinho, discípulo del famoso astrónomo Abraham Zacuto. No hubo como tal una "junta de matemáticos" pero, excepcionalmente, el Rey decidía que algún astrónomo o cosmógrafo participara en los debates. Si Behaim — citado por el cronista Barros — formó parte de ese grupo asesor, en alguna ocasión, fue con posterioridad a la marcha de Colón a Castilla.

45 Vid. la carta de confirmación de Juan II sobre el descubrimiento de cualquier isla o tierra firme que hallasen, firmada en Lisboa el 24 de Julio de 1486, en Colección documental del Descubrimiento , vol. I, doc. n. ${ }^{\circ}$ 14, págs. 47-51.

46 Porro, Jesús María: "La labor cartográfica de la escuela de Nuremberg durante la primera etapa de los descubrimientos americanos", en Fernando Oliveira e o Seu Tempo: Humanismo e Arte de Navegar no Renascimento Europeu (1450-1650), Patrimonia, Cascais, 2000, pág. 379.

47 Ballesteros Beretta, Antonio: Cristóbal Colón y el descubrimiento de América, Salvat, Barcelona, 1945, pág. 385; Favier, Jean : Los grandes descubrimientos. De Alejandro a Magallanes, FCE, México, 1995, pág. 235. 
Nuremberg, en 1490, recibió el encargo municipal de diseñar un globo terrestre. El voluntarioso trabajo de Behaim fue interesante, pese a algunos defectos y errores; ${ }^{48}$ paradójicamente, el destino hizo que su configuración geográfica estuviera pronto desfasada, como consecuencia de los continuos descubrimientos derivados del primer viaje de Colón.

Pero, entretanto, en paralelo con el retorno de Bartolomeu Dias de su periplo africano, está la cuestión de la presencia de Colón en Lisboa, requerido por D. Juan, ${ }^{49}$ como respuesta a su petición; sabedor el Monarca del interés del nauta por los asuntos relativos a viajes y descubrimientos, y a la espera del regreso de Dias, ¿acaso pensaba ofrecer a un Colón abrumado por las dificultades en Castilla un puesto a su servicio o tenderle un ardid para averiguar las posibles intenciones de los Reyes Católicos en la cuestión atlántica?; ¿intentaba quizá D. Juan disuadir a Colón de realizar su proyecto, eliminando así la posible competencia castellana en la actividad descubridora atlántica $?^{50}$ El propio Colón comentaría que estuvo presente en la presentación y entrega al Rey — por parte de Dias- de la carta-relato sobre el descubrimiento del extremo meridional africano ${ }^{51} \mathrm{y}$, presumiblemente, intentaría informarse sobre los últimos cálculos astronómicos efectuados por los portugueses en África, siendo confundido por el hábil Rey. ${ }^{52}$ Por otro lado, resulta verosímil creer que los Reyes Católicos hubieron de tener sus propios agentes en tierras portuguesas, pues de lo contrario ¿cómo pudieron llegar a Córdoba noticias sobre el plan de Dulmo? Parece lógico pensar que tales agentes debieron ser hombres de mar —válidos para el tipo de información que se deseaba obtener y que, al mismo tiempo, por su menester profesional, no levantaran sospechas- quizás

48 Partiendo de una triple influencia de Ptolomeo, Toscanelli y Martellus, adolece de algunos defectos notables en África y Extremo Oriente; para un estudio del globo es interesante Muris, Oswald: "Der Erdapfel des Martin Behaim”, Ibero-Amerikanisches Archiv, 17, Berlín, 1943.

49 Carta del Rey de Portugal a Cristóbal Colón, firmada en Avís el 20 de Marzo de 1488, en Colección documental del Descubrimiento, vol. I, doc. n. ${ }^{\circ}$ 17, págs. 56 y 57.

50 Estas cuestiones fueron planteadas por Ramos, Demetrio: "El sigilo en la preparación del viaje de Bartolomeu Dias y el paralelo sigilo de la inicial negociación de Colón en España, con los efectos derivados", en Navegaçôes na segunda metade do século XV ..., págs. 31-58.

51 Apostilla n. ${ }^{\circ} 23 \mathrm{~b}$ en d'Ailly: Imago Mundi, cap. VIII, pág. 43 (trad.): "en este año 88 en el mes de diciembre llegó a Lisboa Bartolomé Díaz ... había navegado más allá de lo ya navegado 600 leguas ... hasta un promontorio llamado por él mismo Cabo de Buena Esperanza ... Relató su viaje y lo dibujó legua a legua en una carta de marear para mostrarlo a los propios ojos del serenísimo rey, en todo lo cual yo intervine".

52 Ibidem; "en este lugar [el Cabo de Buena Esperanza] descubrió por el astrolabio que se hallaba 45 grados más allá de la línea equinoccial”. A Colón le ocultaron la latitud real de $34^{\circ} 30^{\prime}$. 
andaluces, si bien más probablemente "vizcaínos" ${ }_{53}$ por la frecuencia de escalas en Lisboa, en sus viajes entre el Mar Cantábrico y la franja atlántica andaluza; por su perfil y antecedentes Juan de La Cosa pudo haber sido uno de esos hombres..$^{54}$

Asegurada la apertura de la ruta hacia la India, el prudente D. Juan, necesitado de concentrar los esfuerzos en la empresa africana y no interesándole roces ni disputas con Castilla por la cuestión de los viajes atlánticos al occidente, rechazó definitivamente el proyecto colombino, por lo que Colón tuvo que concentrar sus esfuerzos ante los Reyes Católicos. Durante su primera estancia en Castilla había entrado en contacto con Pedro Vázquez de la Frontera, quien fuera piloto en uno de los viajes de Teive y animó a Cristóbal a proseguir en su intento. ${ }^{55}$ Colón tuvo que esperar al final de la guerra de Granada, madurando su proyecto; así, tras unas largas y duras negociaciones - que, como en Portugal, contaron con el dictamen negativo de la junta convocada al respecto, si bien él gozó de la simpatía y el apoyo de la Reina - fueron fijados los privilegios y obligaciones de su empresa en las Capitulaciones de Santa $\mathrm{Fe}$, cuya rápida y extraña tramitación respondió a la necesaria reserva impuesta en un asunto como ese, de Estado, y al que por sus implicaciones debía concedérsele gran importancia. Una vez afianzada la faceta jurídica-política, Colón se preocupó por el montaje económico y material de la empresa, para lo cual se fijó en la estructura de la expedición africana de Dias. ${ }^{56}$

En agosto de1492 partió Colón hacia el Extremo Oriente, con la idea de cruzar el Atlántico hasta conseguirlo. La travesía fue tranquila, pero tan larga sin encontrar tierra, que la tripulación comenzó a angustiarse pensando en el difícil retorno. Extrañado de no hallar islas durante el trayecto, Colón debatió su plan con Martín Alonso Pinzón, argumentándolo sobre

53 Término que en la época se utilizaba, en amplio sentido, para aludir a las gentes de las villas marineras de la fachada cantábrica.

54 Así lo cree Ramos: "El sigilo ...”, pág. 51, apoyándose en la opinión de Ballesteros Beretta, Antonio: Juan de la Cosa y la marina cántabra, Santander, 1948, pág. 139, donde argumenta que el origen del bienestar económico de La Cosa procedió de los rescates de Guinea. A propósito de las actividades de los vizcaínos en Portugal, se preparaba una armada de castigo, como se ve por la instrucción del 23 de noviembre de 1487: Ramos: "El sigilo ...", pág. 51.

55 Declaración de Fernando Valiente en los Pleitos Colombinos, EEHA, Sevilla, 1967, tomo VIII, p. 339.

56 Tal hecho (utilización de tres carabelas, idea de partir en el mes de agosto y llevar un intérprete de árabe y hebreo, frente a los negros que llevó Dias) demuestra que hubo intencionalidad y no casualidad, y que, con sus limitaciones aumentadas por su fuga a Castilla, también Colón supo de ciertos detalles relativos a las navegaciones portuguesas. 
una carta ${ }^{57}$ y cuando en octubre los expedicionarios llegaron a las Lucayas, el aspecto de aquellas islas, tan diferentes a las conocidas, les hizo plantearse si estaban en otro mundo ${ }^{58}$ pero ¿cuál?; para Colón tenía que corresponder a la antesala de las tierras del Gran Khan, si bien el aspecto y desnudez de los indios le asombró mucho ${ }^{59}$ — como a sus hombres - creando en él las primeras dudas sobre aquella gente y el lugar: su total desconocimiento de las armas metálicas evidenciaba que no habían tenido relaciones con musulmanes ni chinos; así pues, a lo sumo se trataba de islas y gentes relativamente cercanas a aquellas otras de la Especiería. Colón tomó indios como guías y futuros intérpretes (ni siquiera el suyo había podido entenderse con ellos) y continuando su exploración llegó a Cuba a la que consideró ser el Cipango, primero, y más tarde una península del extremo asiático. En su navegación de cabotaje por el litoral septentrional de $\mathrm{La}$ Española Colón creía encontrarse no lejos del Cathay ${ }^{60}$ por lo que más tarde o más temprano tendría que toparse con gentes civilizadas del Extremo Oriente. Una vez decidido el regreso, en enero de 1493, el viaje fue largo y penoso hasta recalar en Lisboa. Allí Colón fue recibido por un solícito Juan II al que tuvo que relatar, con las lógicas cautelas, los pormenores de la empresa; ${ }^{61}$ el Monarca le hizo saber que reclamaría sus derechos de pertenencia de las tierras descubiertas, ante los Reyes Católicos, amparándose

57 La enigmática y famosa carta de Colón, quizás la que le atribuyó La Roncière, aunque es más probable que fuera una copia de la de Toscanelli. En el diario del Primer Viaje (25 de septiembre) figura "una carta ... donde, segund pareçe, tenía pintadas el Almirante ciertas islas por aquella mar", Colón, Cristóbal: Los cuatro viajes. Testamento, ed. de Varela, Consuelo, Alianza Ed., Madrid, 1986, pág. 54. La denominada "Carta de Colón”, que estudiara el primero La Roncière, Charles de: La Carte de Christophe Colomb, París, 1924, se encuentra depositada en la Biblioteca Nacional de París.

58 En el diario (13 de octubre) describe Colón la isla que nombró San Salvador: "es bien grande y muy llana y de árboles muy verdes y muchas aguas y una laguna en medio muy grande, sin ninguna montaña, y toda ella muy verde qu'es plazer de mirarla”, Los cuatro viajes ... pág. 64.

59 En su primera impresión sobre los lucayos (12 de octubre) expresa Colón "todo tomavan y daban de aquello que tenían de buena voluntad, mas me pareció que era gente muy pobre de todo. Ellos andan todos desnudos", Los cuatro viajes..., pág. 62.

60 "Después que yo llegué a la Juana seguí la costa della al poniente y la hallé tan grande que yo pensé que no sería ysla, salvo tierra firme, y que sería la provinçia del Catayo; ni podría aver dello notiçia", carta del Almirante a los Reyes Católicos escrita en el Océano, el 4 de marzo de 1493, en Colección documental del Descubrimiento, vol. I, n. ${ }^{\circ}$ 42, pág. 273.

61 La crítica no ha mantenido una postura unánime respecto al doble tema de la intencionalidad o no de Colón al recalar en Lisboa y así fue el propio Almirante quien — por despecho y revancha- planteó el éxito de su viaje al monarca luso, o bien, fue éste quien con astucia y agasajos consiguió, del descubridor, la información deseada. Parece más prudente pensar en una realidad intermedia y que Colón optara por relatar — con las oportunas reservas — su viaje al Rey, ante la imposibilidad de eludir el tema. En todo caso, el testimonio que ofrece el Almirante en su diario del Primer Viaje, págs. 198-201, es lo suficientemente ambiguo como para no resolver ambas dudas. 
en las bulas papales. Ya en Andalucía, el Almirante notificó por carta lo más rápidamente posible a los Reyes su regreso y las intenciones portuguesas.

\section{La crisis diplomática. Estrategias e ideas geográficas}

Durante los meses de marzo y abril se rumoreó que los lusos preparaban una armada ipara tomar posesión de lo descubierto por Colón o quizás para cortarle el paso en el caso de que realizara otro viaje? Evidentemente, no podía desdeñarse la posibilidad de una guerra entre Castilla y Portugal; ${ }^{62}$ por añadidura, era bien inquietante la defección de los dos marineros portugueses participantes en el periplo colombino. ${ }^{63}$ De inmediato se activaron en ambas cortes los mecanismos diplomáticos, pues el contencioso que se vislumbraba aconsejaba actuar con la máxima prudencia: en ese contexto habría que situar la expedición de sendas reales provisiones, a finales de marzo y de abril, por las que los Reyes Católicos prohibían a sus súbditos viajar a las nuevas tierras descubiertas o a las pesquerías del Cabo Bojador sin su previa licencia. ${ }^{64}$ Por su parte, el Consejo Real acordó proponer a Juan II que se armara una flota, bien para bloquear el posible paso a las Indias de los súbditos castellanos, desde los puertos andaluces, ${ }^{65}$ bien para adelantarse a Colón en otro posible viaje transoceánico hacia las Indias; en cualquier caso, se trataba de una medida peligrosa, que respondía más a un refuerzo - mediante presión - de la vía diplomática que a una actitud intimidatoria de corte belicista. Los Reyes Católicos reaccionaron enérgicamente, maniobrando en un cuádruple plano: el político (respondiendo a la doble embajada de Duarte de Gama y Ruy de Sande con otra, también doble, a cargo de Lope de Herrera, y Pedro de Ayala y Garci López de Carvajal), el diplomático (solicitando del Papa el reconocimiento de su soberanía sobre los nuevos territorios, otorgados por las correspondientes bulas), el geográficologístico (instando a Colón a partir urgentemente hacia las tierras

62 Al respecto Pérez de Tudela, Juan: "La armada de Vizcaya. Acerca de una razón de fuerza y otros argumentos en el acuerdo de Tordesillas", en El Tratado de Tordesillas y su proyección, Actas del Primer Coloquio Luso-Español de Historia Ultramarina, Valladolid, 1973, vol. I, págs. 33-85.

63 Szaszdi, Adam e Istvan: "La crisis luso-castellana de 1493 por el Mar Oçéano", en Castilla y Portugal en los albores de la Edad Moderna, ed. de la Junta de Castilla y León, Salamanca, 1997, págs. 109-123; en págs. 109-111 citan el dato, reflejado en el Parecer de Badajoz de 1524 (obra de Hernando Colón) y el Memorial de la Mejorada de 1497 (escrito por Cristóbal Colón).

64 Reales Cédulas fechadas en Barcelona el 30 de marzo y el 27 de abril de 1493, Colección documental del Descubrimiento , vol. I, n. ${ }^{\circ} 48$ y 50, págs. 285-286 y 287 respectivamente.

65 Pérez de Tudela: "La armada ...", pág. 53 y Pina, Ruy de: Chronica d'El Rey D. Joâo II, Atlántida, Coimbra, 1950, cap. LXVI. 
descubiertas, enviando información geográfica lo más precisa posible, cara a las presumibles negociaciones) y el militar (previniendo al Duque de Medina Sidonia que tuviera aparejadas sus carabelas y ordenando el apresto de una armada en Vizcaya $\left.{ }^{66}\right)$. En la práctica - aunque el peligro del desencadenamiento de operaciones militares se mantuvo latente- se impuso la vía diplomática (aparte del respeto mutuo, porque ninguna de las dos cortes estaba interesada en provocar una guerra). El problema que se planteaba respondía en el fondo a una doble discrepancia (jurídica y diplomática), motivada por las diferentes interpretaciones del Tratado de Alcáçovas, ${ }^{67}$ que a su vez fue rápidamente superado con las nuevas negociaciones. ${ }^{68}$ La posición de Isabel y Fernando era más sólida gracias a la expedición de las bulas pontificias, pero faltaba por esclarecer un dato fundamental: la situación geográfica de las nuevas tierras descubiertas, incluyendo - si fuera posible - datos astronómicos fiables; por ello, los Reyes informaron al Almirante sobre sus intenciones: debía remitir la carta náutica que le habían encargado elaborar y prepararse para partir con rapidez, ${ }^{69}$ si bien debía evitar acercarse a la costa portuguesa - para no provocar recelos- y procuraría interceptar las carabelas lusas que, supuestamente, fueron enviadas para inquirir sobre lo descubierto; además, para que la jurisdicción sancionada por el Papa incluyera el meridiano de demarcación que deseaban fijar en la Corte, era esencial la

66 De aquella febril actividad da idea el hecho de que la carta a Medina Sidonia fue expedida en Barcelona el 2 de mayo de 1493 y la armada de Vizcaya fue aprestada durante los meses de mayo y junio en Bermeo, Colección documental del Descubrimiento , vol. I, págs. 289 y 290 y Pérez de Tudela: "La armada ...", pág. 59, respectivamente.

67 Culpa, a su vez, de la ambigüedad en las delimitaciones de soberanía atlántica: a Portugal le correspondía "la posesion ... tierras, rrescates de guinea ... e qualesquier otras yslas, costas, tierras descubiertas e por descobrir, falladas e por fallar, islas de la Madera, Puerto Sancto e Desierta, e todas las islas de los Açores e islas de las Flores, e asy las islas de Cabo Verde e todas las islas que agora tiene descubiertas, e qualesquier otras islas que se fallaren o conquirieren de las yslas de canaria para baxo contra Guinea, porque todo lo que es fallado e se fallare, conquerir o descobrir ... allende de lo que ya es fallado, ocupado, descubierto, finca a los dichos Rey e prinçipe de Portogal e sus Reynos, tirando solamente las islas de Canaria, Scilicet: Lançarote, Palma, Fuerteventura, la Gomera, el Fierro, la Graçiosa, la Gran Canaria, Tenerife; e todas las otras islas de Canaria ganadas e por ganar, las quales fincan a los Reynos de Castilla", Capítulos relativos a las posesiones y navegaciones de castellanos y portugueses en el Atlántico (Alcáçovas), refrendados en Toledo el 6 de mayo de 1480, en Colección documental del Descubrimiento, vol. I, n. ${ }^{\circ}$ 12, págs. 41-45 (cit. en pág. 43).

68 Ya el 12 de julio de 1493 los Reyes informaban a Colón, por carta datada en Barcelona, del comienzo de las negociaciones con Portugal, congelándose la utilización de armadas, y le instaban a preparar con rapidez su partida para las Indias, Colección documental del Descubrimiento, vol. I, n. ${ }^{\circ} 134$, págs. 436 y 437.

69 Carta de la Reina a Colón, fechada en Barcelona, el 5 de septiembre de 1493, en Colección documental del Descubrimiento, vol. I, n. ${ }^{\circ} 169$, págs. 483 y 484. 
opinión de Colón, el cual debía refrendarla junto a una carta graduada, con la ayuda si fuere preciso de un astrólogo, ${ }^{70}$ para ello, en la Corte se habían adelantado solicitando la opinión de un cosmógrafo tan reputado como Jaime Ferrer. ${ }^{71}$ Los delegados portugueses habían solicitado una demora de dos meses en la partida de cualquier armada y los Reyes Católicos pensaban aprovechar ese plazo para afianzar los aspectos geográficos y científicos de su plan.

El problema que debía solventar Colón, para cumplir el citado encargo, no era nada fácil de superar, pues ni su carta atlántica, ni el boceto que había elaborado sobre la costa noroeste de La Española eran válidos para ello. La primera debió ser la misma que llevaba su hermano Bartolomé cuando — antes de la aprobación del proyecto colombino- viajó a Inglaterra para entrevistarse con Enrique VII en su intento frustrado por conseguir su patrocinio; su desarrollo atlántico contenía los litorales de Europa y África (hasta la altura del Congo), los archipiélagos conocidos y algunas islas míticas situadas al noroeste (Brasil, Siete Ciudades, Frixlanda) y en la parte baja, al suroeste de Cabo Verde (diversas islas pequeñas con un trazado apenas perceptible). También es posible que esa carta fuera una copia de la de Toscanelli, con su "clásico" desarrollo atlántico: los litorales de la Península Ibérica y el noroeste de África enfrentados a los del Cathay y Mangi; en medio, la inmensidad oceánica, con numerosas islas cercanas al litoral del Extremo Oriente, y las de Antilia - equidistante entre las Canarias y el Cipango- y San Brandán, situada al suroeste de la anterior y al sureste del Cipango. Puesto que Colón no encontró ninguna isla hasta llegar a las Lucayas, las que figuraban en su mapa no podían servirle como referencia.

70 Así figura en la carta de los Reyes a Colón, fechada en Barcelona el 5 de septiembre de 1493, en Colección documental del Descubrimiento, vol. I, n. ${ }^{\circ} 174$, págs. 488-490: "que lo que esta en medio desde la punta que los portogueses llaman de buena esperança ... fasta la raya que vos dixisteis que deuia venir en la bulla del papa, piensan que podra aver yslas e avn tierra firme ... se cree que seran muy prouechosas y mas ricas que todas las otras ... vos rogamos que luego nos enbieys vuestro paresçer enello, porque sy conviniere y os paresçiere ... se hemiende la bulla ... Y porque para bien entenderse mejor este vuestro libro avriamos menester saber los grados en que estan las yslas y tierra que fallasteis y los grados del camino por donde fuysteis, por seruiçio nuestro que nos lo enbieys luego y asy mismo la carta que vos rogamos que nos enbiasedes ... muy conplida y escriptos con ella los nonbres y sy vos paresçiere que non la deuemos mostrar nos lo escreuid. Y platicando aca enestas cosas nos paresçe que seria bien que lleuasedes con vos un buen estrologo".

71 Carta del Cardenal Mendoza a mosén Jaime Ferrer, fechada en Barcelona el 26 de agosto de 1493, en Colección documental del Descubrimiento, vol. I, n. ${ }^{\circ} 168$, págs. 482 y 483: "rogamos vos que ... vengais aquí a Barcelona, y traed con vos el Mapamundi y otros instrumentos si teneis tocantes a cosmografia". 
A finales de septiembre partió Colón con destino a las islas y tierras que hallara en su anterior viaje. Casualmente, apenas dos meses antes había regresado a Lisboa Martín Behaim portando una carta de Hieronimus Münzer - afamado médico y humanista conocido como Monetarius - por la que recomendaba al bohemio, ante el Monarca, para participar e incluso dirigir una expedición lusa hacia las Indias navegando por Poniente; ${ }^{72}$ es evidente que ni en el momento de la salida de Behaim de Nüremberg, ni al presentarse ante D. Juan, sabía nada —ni tampoco sus paisanos- del viaje de Colón y su exitoso regreso. Con su proverbial habilidad y agudeza, el Monarca pudo haber sentido, en un primer momento, la tentación de aceptar el plan, pues la carta de Monetarius podía ser esgrimida como coartada válida para argumentar que la Corte portuguesa ya se había planteado la viabilidad de realizar el viaje al Extremo Oriente por Occidente, antes de que el proyecto de Colón fuera aceptado por los Reyes Católicos $;{ }^{73} \sin$ embargo, el Rey optó por la prudencia ante la de por sí suficientemente compleja situación política-diplomática; consecuentemente, rechazó la sugerencia.

En aguas del Océano, en noviembre de 1493, la armada de Colón efectuó un minucioso reconocimiento en el ámbito de las Pequeñas Antillas, sin encontrar indicios de carabelas portuguesas, que tampoco fueron vistas en la navegación de cabotaje de Puerto Rico. ${ }^{74}$ En esa tesitura y ya en La Española, entre finales de noviembre y de enero de 1494 fue el tiempo de que dispuso el Almirante para cumplir el encargo real de elaborar la carta sobre sus descubrimientos, ${ }^{75}$ puesto que al comenzar febrero zarpaba la flota de regreso a España, al mando de Antonio de Torres quien portaba ya el enigmático y pre-

72 La carta, fechada en Nuremberg el 14 de julio de 1493, aparece traducida al portugués en Colección documental del Descubrimiento, vol. I, n. ${ }^{\circ} 141$, págs. 450-452; hay texto en español en Calero, Francisco: "Jerónimo Münzer y el descubrimiento de América", Revista de Indias, LVI, Madrid, 1996, págs. 279-296, y algunas reflexiones en Porro: "La labor cartográfica ...", págs. 382 y 383 .

73 Tal posibilidad ya fue hábilmente planteada por Ballesteros: Cristóbal Colón ..., , pág. 387.

74 Como señalan Szaszdi, Adam e Istvan: "La crisis ...", pág. 120, "las decisiones y la acción del Almirante en aguas caribeñas se supeditan a dos cometidos: el levantar una carta geográfica de los descubrimientos, con los nombres indígenas de las islas y sus coordenadas, así como el reconocer, rastrillar, las islas en busca de la anunciada presencia de las carabelas portuguesas".

75 Aunque no experto, Colón no era nuevo en el arte de elaborar cartas; hay un resumen de la cuestión en Varela Marcos, Jesús: "La cartografía del Segundo Viaje de Colón y su decisiva influencia en el Tratado de Tordesillas", en El Tratado de Tordesillas en la Cartografía Histórica, Sociedad V Centenario del Tratado de Tordesillas, Valladolid, 1994, págs. 88-90; la cuestión de la carta encargada a Colón por los Reyes ya había sido planteada por Pérez de Tudela: "La armada ...", pág. 71. 
ciado documento gráfico ${ }^{76}$ ante la premura de la situación el Almirante tuvo que encargar a varios capitanes y pilotos que efectuaran diversos reconocimientos náuticos (bojeo de La Española) y terrestres, anotando todos aquellos datos que pudieran servirle. ¿Qué aspecto podría tener esa carta?. ${ }^{77}$ Sólo puede deducirse con los datos que proporciona Colón a los Reyes: a la derecha figuraban los litorales de España y África, en la parte izquierda las nuevas islas por él descubiertas; la representación era plana, con sistema de cuadrícula -luego debió tomar como modelo la de Toscanelli-, especificando los grados de latitud y longitud con el módulo de Ptolomeo (que Colón transmite en millas y transforma en leguas marítimas ${ }^{78}$ ); incluía, además, un meridiano trazado a la altura de la recién creada ciudad de la Isabela, separando así lo descubierto en el segundo viaje de lo correspondiente al primero. Por añadidura, de la información colombina se deduce otra característica interesante - aunque errónea- cual es la equivalencia en latitud de La Española con la isla de Gomera, ${ }^{79}$ comentario este que invita a pensar en que la configuración de los archipiélagos atlánticos (los de la fachada euroafricana: Azores, Madeira, Canarias, Cabo Verde, y el antillano, antesala del supuesto Extremo Oriente) y su relación astronómica no pudo diferir mucho de la posterior representación de La Cosa que, curiosamente, adolece del mismo error.

\section{El acuerdo y la continuación de las exploraciones colombinas}

Incluso después de culminados los esfuerzos diplomáticos que motivaron la firma del Tratado de Tordesillas ${ }^{80}$ los Reyes pidieron a Colón una mayor

76 Enigmático, decimos, puesto que tal documento ni fue hecho público ni ha sido encontrado, luego no sabemos como figuraban allí delineadas las islas y tierras correspondientes. Colón manifestaba: "todas estas islas, que agora se an fallado, enbio por pintura con las otras del año pasado y todo en una carta que yo compuse", Cristóbal Colón: Carta-Relación del Segundo Viaje de exploración a América y colonización de la isla Española, en Rumeu de Armas, Antonio (ed.): Manuscrito del Libro Copiador, Madrid, 1989, tomo II, pág. 451.

77 Varela: "La cartografía ...", págs. 95-101 se ocupó de ello, si bien la reconstrucción es meramente hipotética.

78 Carta-Relación ..., págs. 451 y 452: “... un grado, que e contado çinquenta y seis millas y dos terçios que rresponden destas nuestras leguas de la mar, catorze leguas e un sesto ... y contar con el quento del Tolomeo, que a Porçiano [sic] los grados de la longitud con los del equinoçial, diziendo que tanto rresponde quatro grados equinoçiales como çinco, por panuelo de Rodas, los treinta y seis grados ..".

79 Ibidem, pág. 462: “como la pintura hará magnifiesto ... aquí, en La Ysavela estamos más distante de la línea yquinoçial, veinte y seis grados, que todo es con las yslas de Canaria, en espeçial de la Gomera, en un paralelo y no difierençia en la latitud, salvo treinta minutos".

80 Texto completo (Tratado de concordia, llamado de Tordesillas, entre Castilla y Portugal, para la demarcación de sus exploraciones y conquistas en el Océano, firmado en Tordesillas el 7 de junio y corroborado en Arévalo el 2 de julio de 1494) en Colección documental del Descubrimiento, vol. I, n. ${ }^{\circ} 195$, págs. 579-594. 
precisión y abundancia de datos respecto a lo señalado en la carta; ${ }^{81}$ además, el hecho de que su hermano Bartolomé partiera con urgencia - en esa primavera- para comandar tres carabelas de refuerzo hacia las Antillas, permite suponer que también debía tener instrucciones de internarse hacia el equinoccio, en pos de algún posible descubrimiento, ${ }^{82}$ añadiendo de paso al conjunto las oportunas precisiones cartográficas. Que en el ambiente marinero lusocastellano flotaba esa idea de la existencia de islas desperdigadas por el Atlántico es evidente, lo que no está claro es su "ubicación mental" (geográfica) por parte de ambas Cortes - lo cual nos lleva a la polémica y peliaguda cuestión del predescubrimiento del Brasil, difícil de sostener antes del Primer Viaje colombino, si bien posible antes de los acuerdos de Tordesillas (por la porfía lusa en las conocidas 370 leguas como el límite jurisdiccional), aunque no muy probable (por el contrasentido, en ese caso, de la cláusula temporal de las 250 mencionadas, con el consiguiente riesgo de que se adelantaran oficial y jurídicamente los castellanos en el descubrimiento brasileño)—, el caso es que el futuro Adelantado no pudo aportar novedades sobre ello.

Entretanto, el Almirante había decidido reiniciar las exploraciones ampliando su ámbito a Cuba y Jamaica; planeaba costear la Juana por el sur, hacia poniente y así virando al noroeste llegar al Cathay; pero, tras reconocer Jamaica, volvió a cometer el error de supeditar la realidad geográfica antillana a su esquema mental, creyendo encontrarse - en Cuba - en tierra firme del Extremo Oriente, aunque sin una idea clara de a qué altura: ${ }^{83}$ si no mentía en su informe, pensaba regresar a España por Oriente, pero al encontrarse escaso de mantenimientos desistió; ${ }^{84}$ empero, antes de regresar a La Espa-

81 "Algo más querríamos que nos escribiésedes, ansí en que sepamos cuántas islas fasta aquí se han fallado, y a las que habeis puesto nombres, qué nombre a cada una. Porque aunque nombráis algunas en vuestras cartas, no son todas, y a las otras los nombres que les llaman los indios, y cuánto hay de una a otra", Real Cédula de 16 de agosto de 1494, en Colección documental del Descubrimiento, vol. II, n. ${ }^{\circ} 219$, págs. 658-660 (cit. pág. 659).

82 Pérez de Tudela: "La Armada ...", págs. 75 y 56, piensa que tal hecho estaba relacionado con una de las cláusulas del Tratado, por la cual se adjudicaban a los Reyes Católicos las tierras que encontraran los castellanos hasta el 20 de junio de ese año, situadas al occidente de una raya meridiana distante 250 leguas de las islas de Cabo Verde.

83 En su Carta-Relación del viaje de exploración a las islas Española, Cuba y Jamaica, fechada en La Isabela el 26-II-1495, Manuscrito del Libro Copiador, tomo II, pág. 493, expresa Colón: “... fui a la ysla de Jamayca ... y dente bolví a la tierra firme, y seguí la costa della al poniente LXX días [sic], fasta aver pasado a estar mui çerca de la Urea Cheroneço y sé mui çierto que yo estava en la tierra firme, y pasado todas las yslas, y çertificar que la Juana no es ysla ...".

84 Ibidem, pág. 494: “yo provara de bolver a España por Oriente, biniendo a Gangas, dende, y al Signo Arábico, y después, por Etiopía a basta"; suponemos que se refería a pasar por la desembocadura del Ganges - extraña opción, incluso para la concepción geográfica de la época-, pues de lo contrario sólo puede aludir a la navegación de cabotaje por la mítica tierra de Gog. 
ñola, siguió la costa meridional de Cuba, topando con la Península de Zapata ${ }^{85}$ y la del Cabo Corrientes - o quizás la más modesta de la costa sur de Pinar del Río (en torno a San Juan) ${ }^{86}$ - , donde, presumiblemente, se desarrolló el polémico juramento que exigió Colón a sus tripulantes, relativo a la continentalidad de Cuba: ${ }^{87}$ así, las sospechas quedaban acalladas, si bien se mantenía latente la duda - y nos preguntamos si la tuvo el Almirante, y su soberbia o natural vanidad le impidieron reconocerla, o bien si con mayor frialdad intuyó mejor la realidad geográfica y se negó a reconocerla para que no peligraran los privilegios concedidos por las capitulaciones, o quizá su empecinamiento en creer que realmente estaba en los aledaños del Extremo Oriente le impidió plantearse una serena reflexión sobre la geografía que atisbaba-, que se prolongaría en el plano científico, si bien con más tacto, en la correspondencia con Ferrer. En efecto, de forma velada el propio Mosén manifestaría sus dudas, ante los Reyes y ante el mismo Almirante, ${ }^{88}$ sobre la validez del módulo de Ptolomeo y de la concepción astronómica-terrestre colombina. ${ }^{89}$ En el plano de los planteamientos realistas, incluso un amigo suyo, como el Cura de Los Palacios - hombre bien ajeno a los saberes y debates sobre geografía astronómica—, refutaba los cálculos de Colón. ${ }^{90}$

El cambio dinástico en Portugal —al fallecer Juan II y acceder al trono su primo y cuñado Manuel I — tuvo también ciertas implicaciones en las

85 Ibidem, pág. 506: "estava metido en su seno, porque otra bez la tierra del austro boja al oriente; vi unas montañas mui altas ... era un cheroneço tan grande como aquél de la Absinea o como la ysla de Córçega".

86 Ibidem, pág. 507: "navegué al austro, siguiendo la costa de la tierra firme fasta que me llevava al sudueste, y paresçía que avía de llevar este camino gran número de jornadas, y al austro, vía toda la mar quajada de yslas" (los Cayos de San Felipe).

87 Como indica Pérez de Tudela: "La armada ...", pág. 74, puesto que el escepticismo sobre el hecho de que Colón hubiera llegado al Extremo Oriente se mantenía, "en su segundo viaje hubo él de adoptar serias medidas precautorias frente a tales opiniones"; claro que, en la Carta-Relación, no hay ninguna alusión al episodio: "visto que yo avía pasado desde el cavo de Alfaeo justo ... treçientas y veinte y dos leguas, y avía anotado ynfinitas yslas, acordé de tomar la buelta, y no por el camino que yo avía traído, y tornar a Jamayca" (pág. 507); más adelante, el Almirante cita como nombró la península: "al Cheroneço, a que de Sant Juan Evangelista puse nombre" (pág. 508).

88 Por carta del 27 de enero de 1495, fechada en Barcelona y por otra del 5 de agosto de 1495, en Burgos, respectivamente.

89 Ferrer confesaba seguir las pautas de "Strabo, Alfragano, Ambrosi, Macrobi, Teodosi et Euristhenes" y declaraba, respecto a los cálculos de Colón: "según Tolomeo creo es su cuenta",

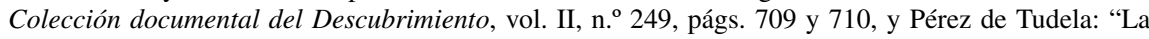
armada ...", pág. 73.

90 Bernáldez, Andrés: Historia de los Reyes Católicos, don Fernando y doña Isabel, Sevilla, 1870, cap. CXXIII, pág. 493: "que por la banda que el Almirante buscaba el Catayo, es de mi creer que con otras mil doscientas leguas, andando el firmamento de la mar e tierra en derredor, no llegase allá, y ansí se lo dije ehice entender yo el año de 1496 [sic] cuando vino en Castilla la primera vez". 
relaciones diplomáticas luso-castellanas, pues el nuevo Monarca era pariente de la Reina Católica y ello facilitó una relación más familiar y menos suspicaz entre ambas Cortes. De ahí que, cuando se evidenciara bien pronto el descrédito sufrido por el Almirante, y se plantearan, en paralelo, las necesidades estratégicas (tanto políticas como económicas) de la Corona, la conjunción de tales hechos aconsejara la ruptura de la exclusiva colombina en lo tocante a los descubrimientos, y la consiguiente apertura de las Indias a varios navegantes y promotores interesados en las nuevas tierras. Puesto que fijar astronómicamente el límite jurisdiccional de ambas Coronas se convertía en una tarea hipotética ${ }^{91}$ — por falta de elementos válidos y objetivos para determinar la longitud - se impuso la práctica más real - aunque con cautelas - de permitir los viajes a Occidente bajo ciertas condiciones (fundamentalmente respetar el ámbito de soberanía portuguesa y varias pautas administrativas, económicas y demográficas).

Al regresar a España en 1496, protestó Colón por el perjuicio que suponía para sus intereses la nueva política diseñada, consiguiendo su revocación que, empero, fue meramente temporal, pues cuando a raíz de los sucesos desencadenados en La Española - tras el tercer viaje colombinosu crédito sufrió una erosión irreversible (ante el afán por consolidar su señorío y sus intereses económicos, descuidando las prioridades de la Corona), los Reyes decidieron aplicar el nuevo sistema de viajes de descubrimiento y rescate.

\section{Conclusiones}

Una vez desarrollado el trabajo, hay varios aspectos que conviene destacar en unas reflexiones finales. En primer lugar, la hegemonía indiscutible del Estado portugués, en el tema de los descubrimientos geográficos y la correspondiente política de sigilo, durante casi todo el siglo XV, para pasar a una fase de mayor equilibrio, con gran dinamismo castellano, justo al comenzar la última década de la centuria. En segundo lugar, debemos

91 De ello dan buena idea la Real Cédula, fechada en Segovia el 30 de junio de 1494, dirigida a D. Gutierre de Toledo, Maestrescuela de Salamanca, para que enviara a la corte personas instruidas en cosmografía; la Carta de Ferrer a los Reyes Católicos, fechada en Barcelona el 27 de enero de 1495 (ya citada), acerca del tratado de partición oceánica con el Rey de Portugal; o la respuesta de los soberanos a Mosén Ferrer, fechada en Madrid a 28 de febrero de 1495, solicitando su presencia en la Corte, para explicar algunos puntos de su argumentación; Colección documental del Descubrimiento, vol. II, n. ${ }^{\circ} 215,249$ y 257 , págs. $655,709-710$ y 747 respectivamente. 
señalar que, pese al notable énfasis en el mantenimiento del secreto de estado, la divulgación sobre lo conocido o descubierto acababa abriéndose camino — si bien, a veces, lenta y dificultosamente-, fenómeno al que no fueron ajenos tres hechos: la vigencia del espionaje - práctica habitual en las relaciones castellano-portuguesas-, la curiosidad científica y cultural (la avidez renacentista por el saber fue un factor de contrapeso en la política de sigilo), y la necesidad de legitimar jurídica y diplomáticamente lo descubierto - con el beneficio no sólo de la posesión reconocida, sino también del prestigio adquirido y la posibilidad de nuevas ventajas políticas y comerciales. En tercer lugar, conviene plantear la importancia de las ideas preestablecidas sobre la imagen del mundo (particularmente en esa etapa transitoria entre la Baja Edad Media y la modernidad), así como la necesidad y dificultad de adaptar aquellos esquemas mentales geográficos obsoletos a los imperativos de la realidad revelada por los sucesivos descubrimientos - un ejemplo muy gráfico sobre ello sería el proceso negociador que condujo al Tratado de Tordesillas-, de ahí la importancia de los nuevos desarrollos cartográficos, auténticos tesoros del fenómeno descubridor.

Aunque las relaciones entre Portugal y Castilla discurrirían con una intencionada cordialidad diplomática durante el reinado de D. Manuel, continuaría no obstante la rivalidad en lo tocante a los descubrimientos geográficos, aderezada por algunos audaces episodios de espionaje. ${ }^{92}$

92 Este trabajo tiene su continuación, pues analizamos lo más sustancial de los siguientes años, así como algunos aspectos fundamentales de lo acordado en Tordesillas, en una ponencia presentada al X Congreso de la Asociación Española de Americanistas, celebrado en Sevilla en julio de 2002, titulada: "Las políticas portuguesa y castellana en el fenómeno descubridor: diplomacia y espionaje. La Cartografía (1492-1500)". 